\title{
NSU
}

Florida

Nova Southeastern University

NOVA SOUTHEASTERN

UNIVERSITY

NSUWorks

College of Psychology: Faculty Articles

College of Psychology

$11-1-1993$

\section{What's In A Label? The Effects of Substance Types and Labels on Treatment Considerations and Stigma}

John A. Cunningham

University of Toronto

Linda C. Sobell

Nova Southeastern University, sobelll@nova.edu

Virginia M. Chow

Follow this and additional works at: https://nsuworks.nova.edu/cps_facarticles

Part of the Psychology Commons

\section{NSUWorks Citation}

Cunningham, J. A., Sobell, L. C., Chow, V. M. (1993). What's In A Label? The Effects of Substance Types and Labels on Treatment Considerations and Stigma. Journal of Studies on Alcohol, 54(6), 693-699.

Available at: https://nsuworks.nova.edu/cps_facarticles/798

This Article is brought to you for free and open access by the College of Psychology at NSUWorks. It has been accepted for inclusion in College of Psychology: Faculty Articles by an authorized administrator of NSUWorks. For more information, please contact nsuworks@nova.edu. 


\title{
What's in a Label? The Effects of Substance Types and Labels on Treatment Considerations and Stigma
}

\author{
JOHN A. CUNNINGHAM, M.A., LINDA C. SOBELL, PH.D. ${ }^{\dagger}$ AND VIRGINIA M.C. CHOW, B.sc. ${ }^{\dagger}$ \\ Addiction Research Foundation, Toronto \& Department of Psychology, University of Toronto, Toronto, Ontario, Canada
}

\begin{abstract}
Visitors $(N=579)$ to a science center read selected scenarios and evaluated the most likely outcome for a hypothetical substance abuser. Respondents were randomly assigned to one of six scenario conditions: a person with one of three different substance abuse problems (alcohol, tobacco, or cocaine) was crossed with two labels reflecting high or low substance dependence. Results indicated that: (1) cigarettes were viewed as a less serious substance abuse
\end{abstract}

problem than were alcohol or cocaine (a person who smoked cigarettes was rated as more likely to recover from his problem, selfchange was regarded as more appropriate and less stigma was associated with smoking than with the other two drugs); (2) nonabstinent recoveries of all types were greeted with skepticism; and (3) recovery was rated as more likely to occur from treatment than from self-change. (J. Stud. Alcohol 54: 693-699, 1993)
$\mathbf{S}^{\mathrm{T}}$ TEREOTYPICAL BELIEFS about substance abusers are common. Dean and Poremba (1983) found that three-quarters of the words used by respondents to describe an "alcoholic" reflected the image of a skid row bum. The impression of a "drug addict"' is similarly negative (Dean and Rud, 1984).

Stereotypical impressions may also affect interactions with substance abusers. Tootle (1987) found that recovered "alcoholics" were not fully socially accepted in the work place. Erickson and Goodstadt (1979) reported that those with a supposed greater criminal record for marijuana possession received fewer postitive responses from potential employers. Sobell and Sobell (1975) found that a harsher penalty was more often recommended when a crime suspect was said to have been drunk and labeled an alcoholic than when not so labeled.

It has also been postulated that the stigma associated with being labeled an alcoholic can be a reason for problem drinkers not wanting to enter treatment (Roizen, 1977; Tuchfeld et al., 1976). In support of this, a recent study

Received: June 23, 1992. Revision: August 17, 1992.

*The views expressed in this article are those of the authors and do not necessarily reflect those of the Addiction Research Foundation. This study was supported, in part, by a studentship from the Medical Research Council, Canada. Portions of the article were presented at the 25th annual meeting of the Association for Advancement of Behavior Therapy, New York City, November 1991.

${ }^{+}$Linda C. Sobell and Virgina M.C. Chow are with the Addiction Research Foundation, Toronto. Linda C. Sobell is also associated with the Departments of Psychology and Behavioural Science, University of Toronto.

Reprint requests should be sent to John A. Cunningham, M.A., Addiction Research Foundation, 33 Russell Street, Toronto, Ontario, M5S 2S1, Canada. of persons who had resolved an alcohol problem without treatment found that $40 \%$ reported they had not sought treatment because of the stigma of being labeled an alcoholic (Sobell et al., 1992). Problems with identifying with the stereotype of an alcoholic have also led some patients to delay seeking treatment (Thom, 1986). Finally, $45 \%$ of people in a general population survey believed that alcohol treatment should be conducted away from a person's home to protect their privacy (Mulford and Miller, 1961).

Stafford and Petway (1977) found that different labels may evoke different levels of stigma. Using semantic differential scales, respondents rated descriptions of an individual labeled as an alcoholic, a drunk, or an unlabeled target. The alcoholic was rated as significantly less reliable, more dishonest and more sick than the drunk target, and both the alcoholic and the drunk were rated as significantly more sour, dishonest, bad, immoral, slow, weak, selfish, hopeless, less respectable and less responsible than the unlabeled target. Similarly, Wallston and colleagues (1976) found that a patient admitted to hospital with a bleeding ulcer who was described as alcoholic was rated by nurses less favorably than the same patient not so described. These labeling effects have also been found to interact with aspects of the target (e.g., employment status) as well as the respondent population (e.g., urban, rural, student or alcoholic) (Kilty, 1981; Kilty and Meenaghan, 1977). Stigmatization is also reported with drug abuse (Dean and Rud, 1984) and cigarette smoking (Cooper and Kohn, 1989; Dion et al., 1990; Goldstein, 1991).

A problem with the labeling research to date is that the amount of reported substance use has not been controlled. This is important as different levels of drinking are associated with different labels (e.g., social drinker, problem drinker, alcoholic) (McKirnan, 1977). In one study which 
controlled for amount, pattern and results of drinking, targets labeled as alcoholic were rated as more negative on psychological attributes (Cash et al., 1984). The alcoholic label produced stigma when the drinking pattern was described as normal (i.e., levels similar to most subjects) as well as abnormal (i.e., more alcohol consumed, hard liquor, drinks alone, severe hangovers and a reckless driving charge). Respondents also reported they wanted less contact with the alcoholic target in social and work situations. Unfortunately, the quantity of drinking in the abnormal condition was very low (i.e., four drinks). The present study used alcohol and drug doses that reflected an abuse profile.

The present study had adults evaluate scenarios that described individuals with different substance use labels (e.g., heavy drinker versus alcoholic) for three different substance types (alcohol, tobacco, cocaine) and who were seeking either an abstinent or a nonabstinent recovery through treatment or on their own. The following issues were addressed: (1) people's beliefs about the appropriateness of self-change and moderate drinking outcomes; (2) the degree of credibility attributed to substance abusers when they make statements about their recovery; and (3) beliefs associated with the abuse of different substances.

\section{Method}

The study was approved by the Ethics Committee of the Department of Psychology, University of Toronto. Subjects 19 years of age or older were recruited at the Ontario Science Center (Toronto, Canada) in response to a poster stating "Take part in a psychology experiment. Topic: What are your beliefs about addictions?" Participants were given a questionnaire and consent form and were asked to follow the instructions on the consent form. Subjects were told that the experiment would take approximately 15 minutes and that their answers would be confidential and anonymous.

Background data and information about the respondent's own substance use were collected. The CAGE, a four-item questionnaire, was used to evaluate whether the subject had ever had an alcohol problem (Mayfield et al., 1974; Smart et al., 1991). Nicotine dependence was assessed by asking the number of cigarettes smoked during an average day and the number of minutes upon waking until smoking the first cigarette (Heatherton et al., 1989). For cocaine, respondents were asked if they had ever tried the drug. After they had completed the questionnaire, respondents were thanked for their participation and any questions about the study were answered.

\section{Subjects}

Of the 606 respondents who volunteered to participate in the study, 26 were dropped because they were less than 19 years of age or failed to give their age. Another respon- dent was dropped because it appeared that he did not take the experiment seriously (e.g., reported that the average male smoker smoked 483 cigarettes per day). The final sample size was 579 .

Differences in demographic variables across conditions were assessed using two-way analyses of variance (ANOVA) for parametric variables and chi-square tests for nonparametric variables. Since none of the variables differed significantly $(\mathrm{p}>.05)$, data were collapsed across all conditions. The respondents' mean $( \pm \mathrm{SD})$ age was $29.1 \pm 9.3$ years (range: 19 to 76 ), and slightly more than half were women $(52.8 \%)$. Educational status was quite high; almost all had completed high school $(95.4 \%)$ and $58.1 \%$ had some university education. Three-quarters (72.1\%) of all respondents resided in Canada with most of the remaining sample $(23.5 \%)$ living in the United States. Almost half $(49.3 \%)$ had never smoked cigarettes, $23.3 \%$ were ex-smokers and $27.4 \%$ currently smoked cigarettes. Of current smokers, the mean ( \pm SD) number of cigarettes smoked per day was $15.9 \pm 11.0$ and the median (mean $\pm \mathrm{SD}$ ) number of minutes upon waking to their first cigarette was $30.0(88.6 \pm 144.9)$. Almost three-quarters $(72.8 \%)$ of respondents were current drinkers with the remainder reporting abstinence $(16.8 \%$ current abstainers, $10.4 \%$ lifetime abstainers). One-quarter (24.7\%) scored two or more on the CAGE, which is suggestive of having had (or having) an alcohol problem. Finally, $24.0 \%$ reported having tried cocaine at least once.

\section{Procedure}

Respondents were randomly assigned to one of six target scenario conditions: the scenarios involved a man who had one of three different substance use problems (alcohol, tobacco or cocaine) crossed with two labels reflecting high or low substance dependence in a between-subjects design. Other aspects of the target scenario (drug quantity, family and job situation) were kept constant. The following is an example of one of the scenarios (alcohol, low-dependence label):

John Smith is a heavy drinker. On week nights he usually has from five to ten beers. On weekends, John has from ten to fifteen beers a day. John is the manager of a small department store. He is married with two children, aged six and ten. In the last year, John has thought about how being a heavy drinker is affecting his life. (italics added)

The substance use labels employed in the target scenario and in the questionnaire were as follows. (1) alcohol: "alcoholic"' or "heavy drinker"; (2) tobacco: "heavy chain smoker" or "moderate smoker"; and (3) cocaine: "regular cocaine user" or "social/recreational cocaine user." While the labels varied across conditions, the amount of reported substance use was held constant. The levels of use were: (1) alcohol abuser: drank 5 to 10 beers 
$\nabla$ Self-Change

Treatment
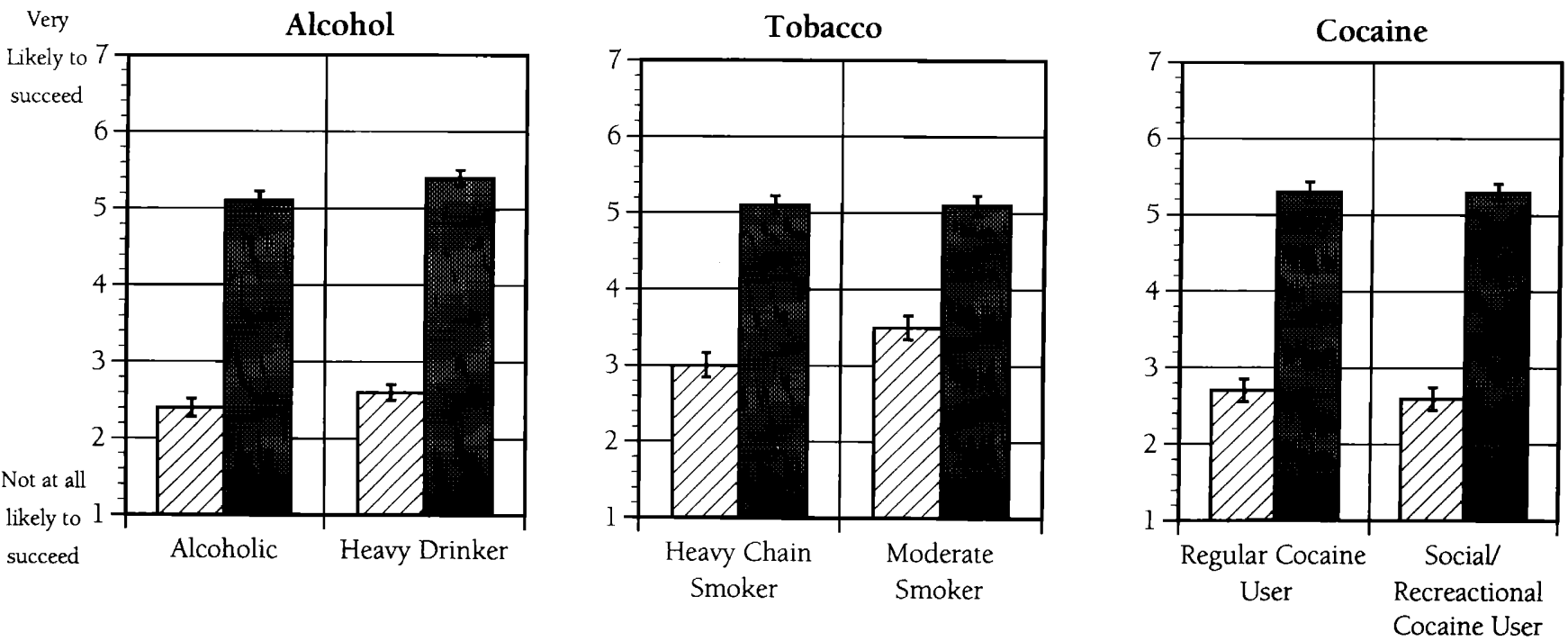

FIGURE 1. Means ( \pm SEs) for ratings of the likelihood of the target's recovery with treatment vs self-change (no treatment)

on week nights and 10 to 15 beers per day on weekends; (2) smoker: smoked about 30 cigarettes a day; and (3) cocaine user: snorted 1 to 2 hits of cocaine a day.

Using 7-point scales, respondents were asked to rate the likelihood of the target's recovery if he tried to resolve his substance use problem with treatment or without (selfchange). The likelihood of recovery was similarly assessed for abstinent and nonabstinent (i.e., moderate use) recoveries within treatment and self-change recoveries. Respondents were also asked how likely they would be to believe statements that the target had resolved his substance use problem through abstinence or through nonabstinence. Respondents further ranked what they thought were the most appropriate treatments for the target (i.e., physician, Alcoholics Anonymous, friends/family, psychiatrist, church, self-change, treatment agency). Lastly, respondents were asked how likely the target would be to experience vocational, legal and marital problems because of his substance use problem and to rate how uncomfortable they would feel being the target's co-worker or inviting the target to a dinner party.

\section{Results}

\section{Treatment outcome questions}

A $2 \times 3 \times 2$ repeated-measures ANOVA compared respondents' ratings of the likelihood of the target's problem resolution through self-change (without treatment) versus through treatment (within subjects) across sub- stance type and label conditions (between subjects). Since the distribution of responses for the question regarding self-change was positively skewed, the analysis was performed on natural logarithm transformed data. The observed means and standard errors are shown in Figure 1.

A main effect was found for substance use labels $(F=5.04,1 / 568 \mathrm{df}, p=.025)$. The low dependence label target was rated as more likely to succeed at recovery than the high dependence label target (observed means $[ \pm \mathrm{SD}]=4.1 \pm 0.9$ and $4.0 \pm 1.1$, respectively). There was also a main effect of self-change versus treatment $(F=1030.761 / 568 \mathrm{df}, p<.001)$, indicating that the treated target was rated as more likely to succeed than the target who attempted to change on his own. Finally, there was a main effect of substance type $(F=6.62,2 / 568 \mathrm{df}$, $p=.001)$, and a significant interaction between treatment and substance types $(F=15.89,2 / 568 \mathrm{df}, p<.001)$. Scheffé post hoc pairwise comparisons found five significant $(p<.05)$ differences. In the self-change condition, respondents in the tobacco condition rated the target as more likely to succeed than those in the alcohol or cocaine condition. In the treatment condition, the likelihood of the target succeeding did not differ significantly across substance types $(p>.05)$. Finally, for all substance types, recoveries with treatment were rated as more likely to succeed than those without treatment $(p<.05)$.

A $2 \times 2 \times 3 \times 2$ repeated-measures ANOVA was conducted comparing a different set of questions that crossed self-change versus treatment and abstinent versus nonabstinent resolutions (within-subject variables) with substance 
Abstinent Recovery

Non-Abstinent Recovery
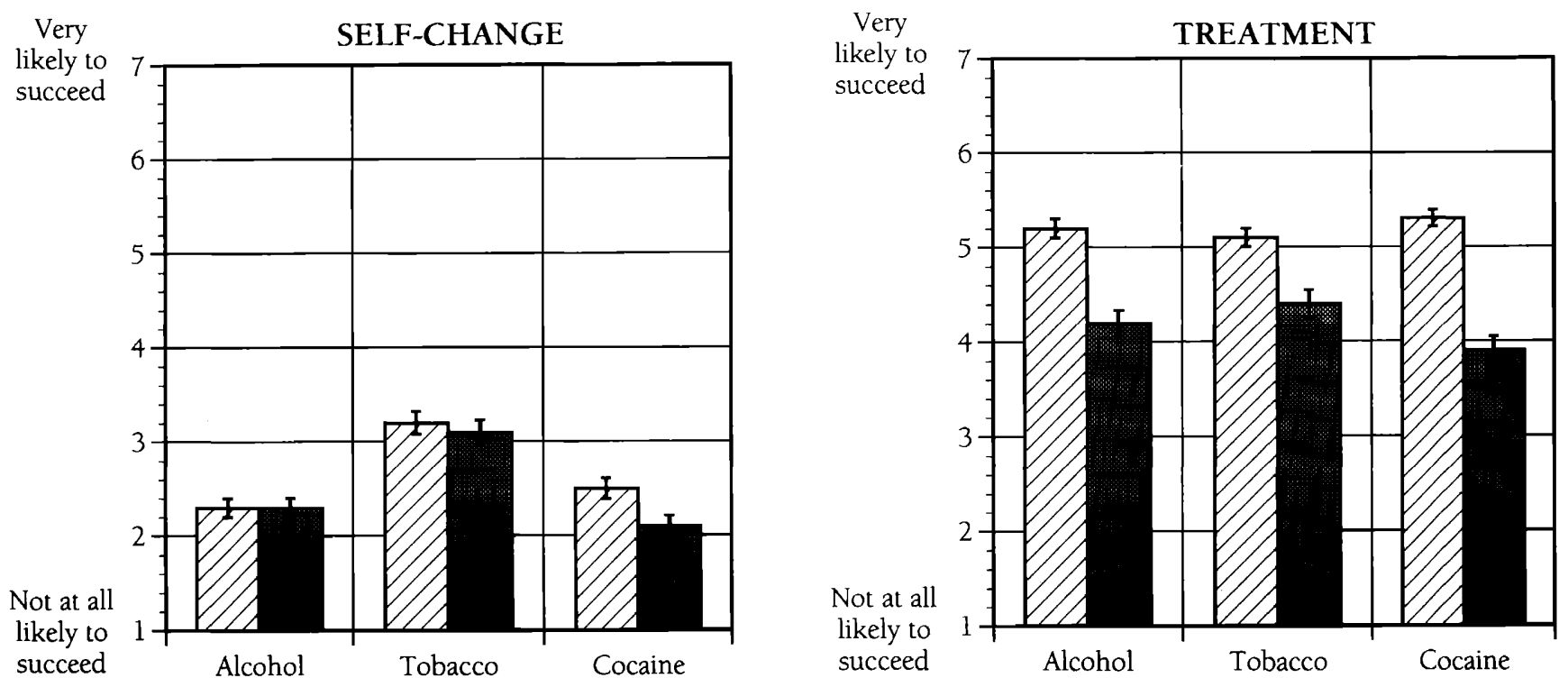

Figure 2. Means ( \pm SEs) for ratings of the likelihood of the target's recovery with treatment vs self-change (no treatment) and with abstinent vs nonabstinent resolutions

type and label conditions (between-subject variables). Natural logarithm transformed data were used in this analysis because responses to the self-change questions (abstinent and nonabstinent resolutions) were positively skewed. The observed means and standard errors are shown in Figure 2.

There was no significant main effect for substance use labels $(F=1.8,1 / 562 \mathrm{df}, p>.05)$, but abstinent resolutions were rated more likely to succeed than were nonabstinent resolutions $(F=951.6,1 / 562$ df, $p<$ $.001)$. Also, resolutions through treatment were rated more likely to succeed than were those through selfchange (without treatment) $(F=77.2,1 / 562 \mathrm{df}, p<$ $.001)$. There was a significant main effect for substance type $(F=15.59,2 / 562 \mathrm{df}, p<.001)$ and a significant interaction between abstinence and substance type $(F=$ $23.3,2 / 562 \mathrm{df}, p<.001)$. Scheffé post hoc pairwise comparisons revealed eight significant $(p<.05)$ differences. When abstinence was selected, respondents in the tobacco condition rated the target more likely to succeed at recovery as compared to respondents' ratings in either the alcohol or cocaine conditions. When nonabstinence was selected, all substance types differed significantly $(p<.05)$ with the smoking target rated as the most likely to recover and the cocaine target least likely. Abstinent resolutions were rated as more likely to succeed than nonabstinent resolutions for all substances $(p<.05)$. There was also a significant interaction between treatment and substance types $(F=5.85,2 / 562 \mathrm{df}, p=.003)$. Scheffé post hoc tests found five significant pairwise comparisons $(p<.05)$. When self-change was chosen, respondents in the tobacco condition rated the target as more likely to succeed than respondents who were rating the alcohol or cocaine target. However, when treatment was chosen, likelihood of success did not differ significantly $(p>.05)$ by substance type. Resolutions through treatment were rated as more likely to succeed than those through selfchange for all substance types $(p<.05)$. Finally, there was significant interaction between self-change versus treatment and abstinent versus nonabstinent resolutions $(F=74.0,1 / 562 \mathrm{df}, p<.001)$. Scheffé post hoc tests found four significant pairwise comparisons $(p<.05)$. Abstinent resolutions were rated more likely to succeed than nonabstinent resolutions and treatment was rated as superior to self-change. The difference between abstinent and nonabstinent resolutions was not as great when the target attempted self-change compared to when treatment was used.

\section{Treatment recommendations}

Respondents were asked to rank order seven possible treatments $(1=$ most favored; $7=$ least favored $)$. Table 1 presents the mean rank for each treatment for each substance type. For respondents in the alcohol condition, AA and a treatment agency were the two most favored treatment choices; self-change was the least favored. For respondents in the tobacco and cocaine conditions, a treat- 
TABLE 1. Mean rank treatment recommendations for each substance type

\begin{tabular}{lccc}
\hline & \multicolumn{3}{c}{ Mean rank within substance type ${ }^{a}$} \\
\cline { 2 - 4 } Variable & Alcohol & Tobacco & Cocaine \\
\hline Treatment agency & 2.2 & 2.1 & 1.5 \\
Physician & 4.4 & 3.0 & 3.5 \\
AA & 1.9 & $\mathrm{NA}^{b}$ & $\mathrm{NA}^{b}$ \\
Friends/family & 4.1 & 3.6 & 4.0 \\
Psychiatrist & 4.1 & 4.0 & 3.8 \\
Church & 5.6 & 5.9 & 5.5 \\
By himself/herself & 5.7 & 3.6 & 5.5 \\
\hline
\end{tabular}

${ }^{a}$ Alcohol: 1 = most favored treatment; $7=$ least favored treatment. Tobacco and cocaine: $1=$ most favored treatment; $6=$ least favored treatment.

${ }^{b}$ Not applicable.

ment agency or physician were rated as the treatment of choice and the church least favored.

\section{The credibility and stigma of substance abuse}

A $2 \times 2 \times 3$ repeated-measures ANOva compared the likelihood that the target would be believed $(1=$ not at all likely; $7=$ very likely) if he told the respondent that he had an abstinent or nonabstinent resolution (within subjects) across substance type and label conditions (between subjects). There was a significant main effect for substance type $(F=48.0,2 / 559 \mathrm{df}, p<.001)$. Post hoc Scheffé tests revealed that respondents in the tobacco condition rated the target as significantly $(p<.05)$ more likely to be believed than those in the alcohol or cocaine conditions (means $[ \pm \mathrm{SDs}]=4.5 \pm 1.4,3.3 \pm 1.4$, $3.2 \pm 1.4$, respectively). There was also a main effect for abstinence versus nonabstinence $(F=161.4$, $1 / 559 \mathrm{df}, p<.001)$. Abstinent resolutions were more likely to be believed than were nonabstinent resolutions (means $=4.3 \pm 1.8,3.1 \pm 2.0$, respectively).

An overall stigma score was formed by combining the following five questions: (1) "If John Smith's supervisor at work knew that John had an alcohol problem, how likely do you think this would be to negatively affect John's career?"; (2) "If John Smith was your co-worker, how uncomfortable would his continued drinking make you feel?"; (3) "How uncomfortable would you feel about inviting John Smith to a dinner party?"; (4) "How likely do you think it would be for John Smith's wife to leave him because of his alcohol problem?"; (5) "How likely do you think it would be for John Smith to get in trouble with the law because of his alcohol problem?', Since each item was scored on a 7-point scale, the composite score ranged from 5 to 35 . Higher scores indicated that respondents believed there was more stigma associated with the target's substance use. A two-way ANOVA revealed a main effect of substance type $(F=293.5,2 /$ $531 \mathrm{df}, p<.001)$. Scheffé post hoc comparisons found that respondents in the tobacco conditions rated the target as significantly $(p<.05)$ less likely to experience stigma because of his substance use than did those in the alcohol or cocaine conditions (means $=16.2 \pm 6.4,28.2 \pm 4.6$, $28.4 \pm 5.0$, respectively).

\section{Discussion}

Substance type significantly affected respondents' ratings about likelihood of recovery. The smoker was rated more likely to recover than the target who abused alcohol or cocaine, especially when the mode of recovery was self-change. However, irrespective of substance type, treatment is perceived as more effective than self-change, abstinent resolutions are seen as superior to nonabstinent resolutions and treatment and abstinent recoveries interact in such a way that when self-change is the mode of recovery abstinent resolutions are rated almost as unlikely to succeed as are nonabstinent resolutions.

Respondents' treatment recommendations shed further light on their perceptions about different substance problems. For alcohol, the favored treatment was Alconolics Anonymous, a finding consistent with other studies (Blum et al., 1989; Caetano, 1987; Mulford and Miller, 1961) and which probably reflects a widespread awareness of this organization (Rodin, 1981). Treatment agencies were the second most favored choice for the target's alcohol problem, and the most favored choice for smoking and cocaine-abuse problems. Self-change was ranked as one of the least favored choices for the alcohol and cocaine-abuse target, while for the smoking target it had a mean rank of fourth and had a modal ranking of one. This finding is consistent with widespread media reports that many cigarette smokers have stopped on their own (Fiore et al., 1990; Office on Smoking and Health, 1988). Collectively, these results indicate that resolutions without treatment are seen as more probable for cigarette smokers compared to individuals with alcohol or cocaine problems.

The perception that recovery with treatment is more likely to succeed than recovery without treatment is in contrast to studies showing that self-change is a common pathway to recovery for alcohol abusers (Fillmore, 1988; Institute of Medicine, 1990; Sobell and Sobell, 1991; Sobell et al., 1992). These findings suggest that respondents were not aware of, or did not have much confidence in, the evidence regarding natural recoveries.

Since smoking was not viewed as likely to cause psychosocial problems (e.g., work, legal, social, familial) compared to alcohol or cocaine abuse, it is possible that respondents did not view the use of cigarettes as substance abuse, a position similar to that taken by the American Psychiatric Association through 1980 (Sobell et al., 1990). Perhaps such attitudes will change as the prevalence of smokers decreases and the remaining smokers acquire a more "die-hard image" (Coambs et al., 1989). The fact that alcohol and cocaine abuse were associated with similar degrees of stigma, particularly in relation to 
legal trouble, was surprising. One explanation is that respondents thought of different legal issues related to each drug (e.g., drunk driving versus drug arrests).

An important reflection of stigma found in the present study was the credibility accorded the target's statement about recovery. The smoking target's claims of recovery were significantly more likely to be believed than those of the alcohol or cocaine abuse targets. Also, assertions of nonabstinent recoveries were greeted with more skepticism than were those of abstinent resolutions. Given the prevalence in the general population of nonabstinent recoveries for alcohol abusers (Fillmore, 1988; Sobell and Sobell, 1991; Sobell et al., 1992), the fact that nonabstinent recoveries are less credible demonstrates another gap between respondents' beliefs and reality.

Fewer label effects were found in this study as compared to past research (Cash et al., 1984; Dean and Rud, 1984; Kilty, 1981; Kilty and Meenaghan, 1977; Stafford and Petway, 1977; Wallston et al., 1976). Previous studies, however, have either failed to mention the amount of the substance used or have indicated use of small amounts. Cash et al (1984), for example, described the target as consuming 2-4 drinks per day, while the present study had the target drinking 5-10 beers on weeknights and $10-15$ beers per day on the weekends. Perhaps the amount reported in the present study was so heavy that it obscured any label effects. Alternatively, it may be that providing extensive drinking or drug use information minimizes the impact of the label. It is also possible that the scenarios used in the present study (i.e., married, middle class with a family) are not consonant with that of an "alcoholic," a "heavy chain smoker," or a "regular cocaine user." Finally, attitudes towards substance abusers may have changed over time, leading to the lack of label effects seen in this study.

Future studies may wish to explore the influence of different target (e.g., low versus high socioeconomic status) and respondent (e.g., educational status) characteristics on treatment ratings. Also, the disparity between respondents' perceptions of how recoveries occur and actual outcomes suggests that research might focus on how such beliefs could be changed.

\section{Acknowledgments}

The authors wish to thank Drs. Jonathan L. Freedman and Mark B. Sobell for their help in this project.

\section{References}

Blum, T.C., Roman, P.M. And Bennett, N. Public images of alcoholism: Data from a Georgia survey. J. Stud. Alcohol 50: 5-14, 1989.

Caetano, R. Public opinions about alcoholism and its treatment. J. Stud. Alcohol 48: 153-160, 1987.
Cash, T.F., Briddell, D.W., Gillen, B. and MacKinnon, C. When alcoholics are not anonymous: Socioperceptual effects of labeling and drinking pattern. J. Stud. Alcohol 45: 272-275, 1984.

Coambs, R.B., Kozlowski, L.T. and Ferrence, R.G. The future of tobacco use and smoking research. In: NEY, T. AND Gale, A. (Eds.) Smoking and Human Behavior, New York: John Wiley \& Sons, Inc., 1989, pp. 337-348.

Cooper, W.H. AND KoHn, P.M. The social image of the young female smoker. Brit. J. Addict. 84: 935-941, 1989.

Dean, J.C. and Poremba, G.A. The alcoholic stigma and the disease concept. Int. J. Addict 18: 739-751, 1983.

Dean, J.C. AND Rud, R. The drug addict and the stigma of addiction. Int. J. Addict. 19: 859-869, 1984.

Dion, K.L., Dion, K.K., Coambs, R. and Kozlowski, L. Smokers and Drinkers: A Tale of Two Stereotypes, Ottawa, Canada: Canadian Psychological Association, May, 1990.

ERICKSON, P.G. AND GoodstadT, M.S. Legal stigma for marijuana possession. Criminology 17: 208-216, 1979.

Fillmore, K.M. Alcohol Use Across the Life Course: A Critical Review of 70 Years of International Longitudinal Research, Toronto: Addiction Research Foundation, 1988.

Fiore, M.C., Novotny, T.E., Pierce, J.P., Giovino, G.A., HatzianDreu, E.J., Newcomb, P.A., Surawicz, T.S. and Davis, R.M. Methods used to quit smoking in the United States. JAMA 263: 2760-2765, 1990.

Goldstein, J. The stigmatization of smokers: An empirical investigation. J. Drug Educ. 21: 167-182, 1991

Heatherton, T.F., Kozlowski, L.T., Frecker, R.C., Rickert, W. AND Robinson, J. Measuring the heaviness of smoking: Using selfreported time to the first cigarette of the day and number of cigarettes smoked per day. Brit. J. Addict. 84: 791-800, 1989.

InstituTE of MEDICINE. Broadening the Base of Treatment for Alcohol Problems, Washington D.C.: National Academy Press, 1990.

KILty, K.M. Drinking status and stigmatization. Amer. J. Drug Alcohol Abuse 8: 107-116, 1981.

Kilty, K.M. and Meenaghan, T.M. Drinking status, labeling and social rejection. J. Soc. Psychol. 102: 93-104, 1977.

McKirnan, D.J. A community approach to the recognition of alcohol abuse: The drinking norms of three Montreal communities. Canad. J. Behav. Sci. 9: 108-122, 1977.

Mayfield, D., Mcleod, G. and Hall, P. The CAGE questionnaire: Validation of a new alcoholism screening instrument. Amer. J. Psychiat. 131: 1121-1123, 1974.

Mulford, H.A. AND Miller, D.E. Public definition of the alcoholic. Q. J. Stud. Alcohol 22: 312-320, 1961.

Office on Smoking and Health. The Health Consequences of Smoking. Nicotine Addiction: A Report of the Surgeon General, 1988, DHHS Publication No. (CDC) 88-8406, Washington: Government Printing Office, 1988.

Rodin, M.B. Alcoholism as a folk disease: The paradox of beliefs and choice of therapy in an urban American community. J. Stud. Alcohol 42: $822-835,1981$.

Rolzen, R. Barriers to Alcoholism Treatment, Berkeley, Calif.: Alcohol Research Group, 1977.

Smart, R.G., Adlaf, E.M. and Knoke, D. Use of the CAGE scale in a population survey of drinking. J. Stud. Alcohol 52: 593-596, 1991.

Sobell, L.C. AND Sobell, M.B. Drunkenness, a "special circumstance" in crimes of violence: Sometimes. Int. J. Addict. 10: 869$882,1975$.

Sobell, L.C. AND Sobell, M.B. Cognitive mediators of natural recoveries from alcohol problems: Implications of treatment. Paper presented at the Annual Meeting of the Association for Advancement of Behavior Therapy, New York, N.Y., November 1991.

Sobell, L.C., Sobell, M.B., Kozlowski, L.T. and Toneatto, T. Alcohol or tobacco research versus alcohol and tobacco research. Brit. J. Addict. 85: 263-269, 1990. 
Sobell, L.C., Sobell, M.B. and Toneatto, T. Recovery from alcohol problems without treatment. In: Heather, N., Miller, W.R. AND Greeley, J. (Eds.) Self-Control and Addictive Behaviors, New York: Maxwell Macmillan, 1992, pp. 198-242.

Stafford, R.A. AND PETway, J.M. Stigmatization of men and women problem drinkers and their spouses: Differential perception and leveling of sex differences. J. Stud. Alcohol 38: 2109-2121, 1977.

Тном, В. Sex differences in help-seeking for alcohol problems1. The barriers to help-seeking. Brit. J. Addict. 81: 777-788, 1986.
TootlE, D.M. Social acceptance of the recovering alcoholic in the workplace: A research note. J. Drug Issues 17: 273-279, 1987.

Tuchfeld, B.S., Simuel, J.B., Schmitt, M.L. ET AL. Changes in Patterns of Alcohol Use without the Aid of Formal Treatment. An Exploratory Study of Former Problem Drinkers, Final Report. Prepared for the National Institute on Alcohol Abuse and Alcoholism, Publication No. PB 259-202, Springfield, Va.: National Technical Information Services, 1976.

Wallston, K.A., Wallston, B.S. and DeVellis, B.M. Effect of a negative stereotype on nurses' attitudes toward an alcoholic patient. J. Stud. Alcohol 37: 659-665, 1976.

\section{CONTROVERSIES IN THE ADDICTIONS FIELD: VOLUME ONE}

\section{Edited by Ruth C. Engs}

This book presents opposing sides of important issues by leading authorities in the addictions field. There are nine sections concerning: the nature of alcoholism and drug addictions; public policies to prevent alcohol abuse; the minimum drinking age; mandatory drug testing in the workplace; restrictions on beverage advertising; the effectiveness of warning labels in preventing alcohol abuse; abstinence for pregnant women; effectiveness of school based alcohol/drug education programs; abstinence as the only treatment for alcoholism.

Foreword and introduction by Ruth C. Engs. Chapters are contributed by: Reid K. Hester and Nancy Sheehy; Donald W. Goodwin; Ting-Kai Li; Robert D. Myers; Howard T. Blane; Herbert Fingarette; Karol L. Kumpfer, Eric P. Trunnell and Henry O. Whiteside; Robin Room; Dwight B. Heath; David J. Hanson; Richard J. Goeman; Robert L. DuPont; Thomas J. Delaney, Jr; Kimberly Neuendorf; Hal Shoup; Donna Polowchena; David Pittman; Sterling Clarren; Ernest Abel and Robert Sokol; Stuart Fors; Louis Gliksman and Cynthia Smythe; Gail Milgram; John Wallace; Martha Sanchez-Craig.

$1990-210$ pages - Paper - ISBN 0-8403-6057-6 $\$ 9.60$ (plus \$2.50 shipping \& handling)

Order from:

American Council on Alcoholism, Inc. 5024 Campbell Boulevard, Suite H Baltimore, MD 21236-6950

Telephone: (410) 931-9393

Fax: (410) 931-4585 